Published in final edited form as:

Cancer. 2016 June 15; 122(12): 1913-1920. doi:10.1002/cncr.29972.

\title{
Genetic anticipation in BRCA1/2 families after controlling for ascertainment bias and cohort effect
}

\author{
Rodrigo Santa Cruz Guindalini, MD ${ }^{1,2,3}$, Andrew Song ${ }^{1}$, James D. Fackenthal, PhD', \\ Olufunmilayo I. Olopade, MD, FACP ${ }^{1}$, and Dezheng Huo, MD, PhD ${ }^{1,4}$ \\ ${ }^{1}$ Center for Clinical Cancer Genetics \& Global Health, Department of Medicine, The University of \\ Chicago, Chicago, IL, USA \\ ${ }^{2}$ Department of Radiology and Oncology, The State of São Paulo Cancer Institute, University of \\ São Paulo Medical School, São Paulo, SP, Brazil \\ ${ }^{3}$ CLION, CAM Group, Salvador, BA, Brazil \\ ${ }^{4}$ Department of Public Health Sciences, The University of Chicago, Chicago, IL
}

\begin{abstract}
Background-Genetic anticipation, the earlier onset of disease in successive generations, has been reported in hereditary breast and ovarian cancer syndrome (HBOC), but little is known about its underlying mechanisms. Ascertainment bias is a reason that has been suggested in previous studies. Likewise, cohort effect, which may be due to environmental factors, can be misinterpreted as genetic anticipation.
\end{abstract}

Methods-We conducted a review of pedigrees in 176 kindreds segregating deleterious mutations in BRCA1/2 genes who had at least two consecutive generations of the same cancer (breast or ovarian). Using mutation probabilities as analytical weights in weighted random-effect models, we calculated generational differences in age of onset of breast/ovarian cancer. Then we further controlled for ascertainment bias by excluding probands and adjusted for birth cohort effect in the anticipation models.

Results-The mean age of breast cancer for the probands' generation was 41.9 years, which was 6.8 years and 9.8 years earlier than the parents' and grandparents' generations, respectively. The anticipation effect for breast cancer remained significant after excluding probands. There was a birth cohort effect: patients born in 1930s and 1940s had breast cancer 5.0 and 7.6 years earlier than patients born before 1920. The difference in breast cancer age of onset across generations was no longer significant after adjusting for birth cohort effect.

Corresponding author: Dezheng Huo, MD, PhD, Department of Public Health Sciences, The University of Chicago, 5841 South Maryland Avenue, MC 2000, Chicago, IL 60637, Phone: 773-834-0843, Fax:773-702-1979, ; Email: dhuo@ health.bsd.uchicago.edu Conflict of interest information: The authors declare that they have no conflicts of interest in the research.

Author Contributions: Rodrigo Santa Cruz Guindalini: Conceptualization, methodology, validation, formal analysis, investigation, data curation, writing - original draft, writing - review and editing, visualization, and project administration. Andrew Song: Software, formal analysis, investigation, data curation, writing - original draft, writing - review and editing, visualization, and project administration. James D. Fackenthal: Conceptualization, methodology, writing - review and editing, and supervision. Olufunmilayo I. Olopade: Conceptualization, writing - original draft, writing - review and editing, visualization, and funding acquisition. Dezheng Huo: Conceptualization, methodology, software, validation, formal analysis, writing - original draft, writing - review and editing, supervision, and funding acquisition. 
Conclusions-The observed anticipation effect was mainly driven by a decrease in age of onset across birth cohorts, underscoring the need for risk reducing interventions that target changing environmental/lifestyle factors in BRCA1/2 carriers.

\section{Keywords}

ascertainment bias; BRCA1/2; cohort effect; genetic anticipation; hereditary breast and ovarian cancer syndrome

\section{INTRODUCTION}

Genetic anticipation is characterized by a reduction in the age of disease onset or an increase in severity of clinical features of a genetic disorder in successive generations. This phenomenon has been studied in a range of diseases, including neurodegenerative disorders such as fragile X syndrome ${ }^{1}$, Huntington's disease ${ }^{2}$, and myotonic dystrophy ${ }^{3}$, and autoimmune diseases such as rheumatoid arthritis ${ }^{4}$, type II diabetes ${ }^{5}$, and Grave's disease ${ }^{6}$. Genetic anticipation has previously been described in several cancer predisposition syndromes, such as retinoblastoma ${ }^{7}$, Lynch Syndrome ${ }^{8,9}$, Li-Fraumeni Syndrome ${ }^{10} 12$, and hereditary breast and ovarian cancer syndrome $\left(\mathrm{HBOC}^{13{ }_{-} 22}\right.$.

Globally, breast cancer is the most common form of cancer in women. Numerous genetic and non-genetic factors affect the likelihood of developing breast cancer, but no other predictor is as powerful as an inherited mutation in the tumor suppressor genes BRCA1/2. More than two decades after these genes were identified, we now know that individuals carrying mutations in $B R C A 1$ and $B R C A 2$ have an average cumulative lifetime risk of $44-78 \%$ and $31-56 \%$ for breast cancer and $18-54 \%$ and $2.4-19 \%$ for ovarian cancer, respectively, making these mutations the strongest breast and ovarian cancer predictors. ${ }^{23} 32$ It is estimated that approximately $5-10 \%$ of breast cancer cases are thought to be hereditary ${ }^{27}$. While other breast cancer susceptibility genes have been identified, mutations in $B R C A 1 / 2$ account for nearly $80 \%$ of inherited breast cancer cases in $\mathrm{HBOC}^{33}$. The variable penetrance of inherited mutations in these genes makes it challenging to estimate the likelihood, age, and site of disease onset in any individual, and therefore it is important to study how to time the initiation of screening and interventions in high-risk women. Several studies examined the anticipation effect in HBOC, reporting a 4 to 18 year younger age of breast cancer onset in successive generations ${ }^{13} 22$. However, most of these studies were based on very small or genetically uncharacterized cohorts. Although there is evidence for the existences of anticipation in HBOC, this phenomenon is not firmly accepted by the scientific community for three reasons: ascertainment bias, cohort effect, and unclear molecular mechanism ${ }^{34}$.

One of the major concerns when assessing genetic anticipation in HBOC is ascertainment bias. The nature of the ascertainment introduces a possible younger onset age bias in that mutation carriers suffering from early onset breast cancer are more likely to fulfill the criteria for genetic testing than mutation carriers with late-onset breast cancer. Within the same family, members with early onset cancer are more likely to be the first to present in the high risk clinics for genetic counseling, i.e. becoming the proband who brings the family 
under the study. As a consequence, ascertainment of mutation carriers in high-risk clinics may lead to an overrepresentation of earlier age of disease onset in younger generation than the older generation. Various statistical approaches can be employed to reduce the impact of this ascertainment bias, such as evaluating not only parent-child pairs but also all the affected family members as well as excluding probands from the calculation. In order to address this issue, Larsen et al $I^{35}$ proposed a random effects model which includes extended pedigree data and unaffected family members. Still, new methods are needed to account for family members who are not tested.

With respect to the cohort effect, penetrance of the disease also depends on nongenetic influences, which can be assessed through the year of birth of mutation carriers. In 2003, King et al. demonstrated that the cumulative risk of breast cancer was significantly higher in BRCA1/2 carriers born after 1940 compared to those born before $1940^{29}$. This birth cohort effect may be due to improvements in cancer programs in high-risk families over time as well as secular changes in environmental and lifestyle risk factors for breast or ovarian cancers.

One molecular basis of genetic anticipation was first discovered in neurodegenerative disorders. Brook et al. observed expanded trinucleotide repeat sequences in myotonic dystrophy with expansion of repeats clearly correlated with an earlier age of onset in succeeding generations ${ }^{36}$. Trinucleotide repeat expansions is now a widely accepted explanation of this phenomenon in some Mendelian diseases. In cancer, the molecular mechanisms behind anticipation likely differ since trinucleotide expansions have never been observed. Recently, telomere shortening has been suggested as an alternative mechanistic explanation. Martinez-Delgado et al. reported a positive correlation between decrease of the telomere length and anticipation in 19 mother-daughter pairs from breast cancer families ${ }^{21}$. This finding is valuable, but the small number of subjects in the study and the use of paired t-tests without correcting for potential bias calls for larger studies for replication. In addition, the hypothetical causal relationship between telomere shortening and genetic anticipation was not found in a study evaluating 244 mismatch repair gene mutation carriers, and it is still under debate in Lynch syndrome ${ }^{37}$.

Given these controversies, we conducted a relatively large study of families segregating deleterious $B R C A 1 / 2$ mutations to evaluate the difference of breast/ovarian cancer onset in successive generations using a novel sophisticated statistical approach to adjust for ascertainment bias and cohort effect.

\section{METHODS}

\section{Study population}

We reviewed pedigrees of consecutive families ascertained in the Cancer Risk Clinic at The University of Chicago between 1992 and 2013 under IRB approved protocols. To be eligible for the study, families had to have a confirmed $B R C A 1$ or $B R C A 2$ deleterious mutation and at least two family members diagnosed with the same cancer (breast or ovarian) in consecutive generations. Of note, the probands did not necessarily have to have been diagnosed with cancer. Clinical and epidemiological data on the affected and unaffected 
members in a family such as family members' age, ages at death, types of cancer, age at cancer diagnosis, and genetic test results were collected.

\section{Statistical analysis}

The study outcome variable was age at breast or ovarian cancer diagnosis. The primary variable of interest was generation. Other covariates included year of birth and type of mutation. To include family members without genetic testing in the model, we calculated the probability of having BRCA1/2 mutation using the BRCAPRO program ${ }^{38}$. The mutation probabilities, or BRCAPRO scores, were used as analytical weights for all family members with breast or ovarian cancer with unknown $B R C A$ status, and patients with known positive mutation status were given a weight of one. Then we applied these analytical weights to the parametric random-effect model for anticipation proposed by Larsen et $\mathrm{al}^{35}$. The basic model is presented below:

$$
T_{i j}=\alpha_{i}+m_{i j} \gamma+x_{i j} \beta+\varepsilon_{i j}
$$

Where, $T_{i j}$ denoted age at diagnosis of individual $j$ in the $i$ th family; $m_{i j}$ denoted the

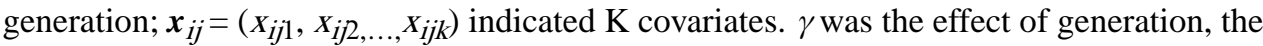
parameter of interest in the study; $a_{i}$ was the family-specific intercept, and $\varepsilon_{i j}$ represented the residuals; both were random terms, assuming normal distribution. The use of mutation probabilities as analytical weights not only improves the statistical power by including all cancer patients in the families, but also reduces potential ascertainment bias. Furthermore, we excluded probands from the model to control for ascertainment bias, as probands are more likely to be self-selected for genetic counseling because of earlier age at diagnosis. To determine whether the genetic anticipation effect is independent of birth cohort effect, we adjusted for year of birth as a covariate in matrix $\mathrm{K}$. We analyzed the data separately for breast cancer and ovarian cancer and further stratified according to genes with mutation (BRCA1 vs. BRCA2).

\section{RESULTS}

\section{Study population}

Of the 532 families who have been tested for $B R C A 1 / 2$ in our database, 300 families had at least one deleterious $B R C A 1 / 2$ mutation segregated. Of these, 176 (34.9\%) met the inclusion criteria that two or more family members have the same cancer (breast or ovarian) in consecutive generations. Characteristics of the probands and their family members diagnosed with cancer are described in Table 1. There are 113 families with BRCA1 mutations and 63 families with $B R C A 2$ mutations. In 155 families, at least two family members had breast cancers, and a total of 579 family members were included in the anticipation analysis of breast cancer. Using the BRCAPRO program, we estimated mutation probabilities for patients without $B R C A 1 / 2$ testing, and predicted the total number of mutation carriers among breast cancer cases was 469 . In 36 families, at least two family members developed ovarian cancer and a total of 81 family members are included in the anticipation analysis of ovarian cancer. The predicted total number of mutation carriers 
among ovarian cancer patients was 78 . Note that 15 families were included in breast cancer and ovarian cancer families analyses.

\section{Anticipation effect with probands included}

In the random-effect model accounting for mutation probabilities and family structure, we found there was a significant anticipation effect for breast cancer among BRCA1/2 mutation carriers (Table 2). Relative to the probands' generation, parents' generation had breast cancer 6.8 years later, and grandparents' generation had breast cancer 9.8 years later, while the children's generation had breast cancer 7.2 years earlier. Subgroup analysis found that the anticipation effect for breast cancer was significant among families with either BRCA1 or BRCA2 mutations (Supplementary Table 1).

When evaluating differences in ovarian cancer age of onset between generations, we found significant anticipation effect for ovarian cancer although the sample size is limited (Table 2): The grandparents' generation and parents' generation were estimated to have ovarian cancer 8.4 years or 4.8 years, respectively, older than the probands' generation, while the children's generation had ovarian cancer 10.5 years earlier than the probands' generation.

\section{Anticipation effect after excluding probands}

After correcting for ascertainment bias by excluding probands (families that did not have at least 2 generations after excluding probands were also excluded from the analysis), the mean age of breast cancer onset in the probands' generation was 41 years. We found that breast cancer age of onset in the probands' generation was 7.0 years and 10.5 years earlier than in the parents' and grandparents' generations, respectively. These differences remained statistically significant, suggesting that ascertainment bias cannot explain the observed anticipation effect (Table 3). Subgroup analysis showed that the anticipation effect for breast cancer existed in both BRCA1 (mean age of onset - probands' generation: 40 years; parents' generation: 45.1 years; grandparents' generation: 50.7 years) and $B R C A 2$ (mean age of onset - probands' generation: 42.8 years; parents' generation: 53 years; grandparents' generation: 52.7 years) mutation families (Supplementary Table 2).

After excluding probands, the anticipation effect for ovarian cancer remained statistically significant, with grandparents' generation having age of onset 8.6 years older than the probands' generation (Table 3).

\section{Jointly modeling anticipation effect and birth cohort effect}

Mutation carriers born after 1950 (mean 1960, range 1950-1981) reached age ranging from 32 to 63 by year 2013, and thus some of them may develop breast or ovarian cancers later. Therefore we excluded birth cohorts after 1950 from the analysis in order to avoid truncation effect. In the univariate random effect model, the anticipation effect was still significant but the effect size was smaller than that in the model of all breast cancer patients (Table 4). The 1930-1949 birth cohorts were more likely to have early-onset breast cancer than the 1855-1919 birth cohort. After adjusting for birth cohort effect in the multivariable random effect model, the anticipation effect (i.e. generational effect) was no longer significant, while the birth cohort effect remained statistically significant. Similarly, we found a birth cohort 
effect for ovarian cancer and the anticipation effect was not significant after adjusting for birth cohort effect, but the sample size for ovarian cancer analysis was limited (Table 4).

\section{DISCUSSION}

In the current analysis, we evaluated multigenerational families with deleterious BRCA1/2 mutations, adjusting for ascertainment bias and cohort effect concomitantly and using individual probabilities of having BRCA1/2 mutations as analytical weights to address and report anticipation phenomenon in HBOC. In agreement with previous reports, we detected statistically significant anticipation effect in breast and ovarian cancers in BRCA1/2 families in our primary analysis (Table 5) and adjusted analyses for ascertainment bias. Nevertheless, as expected, potential biases had a profound influence on these results. By applying statistical approaches, we showed that the significant decrease in age of breast cancer diagnosis over time is due to cohort effect, eliminating the signal of anticipation in breast and ovarian cancer families. This finding suggests that environmental/lifestyle factors rather than genetic changes account for the anticipation effect.

Our study found that mutation carriers born after 1930 had younger onset of breast and ovarian cancers than carriers born before 1930, which is in line with previous studies among BRCA1/2 carriers. ${ }^{29}, 39$ In general, there is evidence of an increase in breast cancer incidence rates in the recent birth cohort, especially in traditionally low risk regions such as Africa, Asia, and South America where rapid urbanization and modernization are underway in the past several decades. ${ }^{40,41}$ This trend likely reflects increasing prevalence of nongenetic risk factors for breast cancer associated with lifestyle changes as well as increased life expectancy and increased detection of asymptomatic disease after mammography screening became routine. ${ }^{40,41}$ The most commonly implicated nongenetic risk factors for the overall increase in breast cancer risk among women born more recently are changes in female reproductive patterns (lower fertility and delayed childbearing), earlier age of menarche, increasing use of oral contraceptives and menopausal hormone therapy, increasing consumption of calorie-dense food and alcohol, physical inactivity, and obesity. ${ }^{42}$ These factors may have had a similar overall effect between BRCA gene mutation carriers and women of the general population. ${ }^{29,}, 32,39,43$ A recent meta-analysis on modifiers in BRCA1/2 mutation carriers showed that age at first live birth, breastfeeding, tubal ligation, oral contraceptives, and smoking are possible risk modifiers. ${ }^{41}$ Further investigation of risk modifiers in mutation carriers based on large consortium will help to fine tune cancer risk estimation.

Several reports have claimed statistical evidence that earlier appearance of breast cancer in successive generations occurs in HBOC due to generational effects. We approached this claim with skepticism. To date, the only universally accepted molecular mechanism to explain anticipation phenomenon in a variety of neurodegenerative diseases - trinucleotide repeat sequences expansion - has never been described in HBOC. In addition, there are no definitive conclusions about an alternative mechanistic explanation such as telomere shortening. Although the positive correlation between the phenomenon of anticipation and telomere shortening has been described, this finding is inconsistent among cancer predisposition syndromes. ${ }^{21,37,44}$ 
Furthermore, haplotype analysis suggests that the origin of some $B R C A 1 / 2$ founder mutations probably occurred at least 50 or more generations ago (>1000 years ago) ${ }^{45,46}$. Considering this estimation, such a large decrease (4 to 18 years) in age of breast cancer onset in successive generations as previously reported ought to lead to juvenile onset cases within a few generations. Despite the fact that juvenile onset cases have been observed in later generations in repeat expansion disorders, no such cases have been observed in BRCA1/2 families.

We acknowledge that the current sample size is still modest and even though a series of statistical approaches have been undertaken to control for several biases, our results must be viewed cautiously given unavoidable biases attending retrospective analyses such as mutational bias and information bias. In order to minimize mutational bias, BRCAPRO scores were used as analytical weights to estimate individual risks of having BRCA1/2 mutations because individuals in earlier generations often did not have genetic testing. To improve the quality of information, the initial counseling session at our institution is preceded by a phone call interview with a genetic counselor. During this conversation, probands are encouraged to gather important information of family members regarding their cancer history in advance as well as to provide pathology reports of affected family members when available. Detailed pedigrees are drawn at the time of the initial visit in a systematic manner using Progeny software (http://www.progenygenetics.com) and are updated at each visit. Lastly, the finding that early-onset of breast cancer in the children's generation should be interpreted with caution since they were born relatively recently (mean year of birth was 1961) and some of them may not have chance to develop cancer yet.

In conclusion, the prediction of age of cancer onset in those carrying mutations causal of HBOC has clinical implications for the age at which surveillance should be initiated and is important for clinical trial design and understanding of fundamental disease mechanisms. Although it has been suggested that genetic anticipation occurs in HBOC, there is no confirmed molecular mechanism to support it, and cohort effect may confound this interpretation. In our study that corrected for these biases, the statistical trend toward earlier age of onset in successive generations was eliminated, indicating that the cohort effect drove the apparent observation of genetic anticipation. Nonetheless, the observed cohort effect has implications for cancer prevention. Interventions to reduce risk by modulating lifestyle/ environmental risk factors such as breastfeeding may be warranted after family based counseling. Our findings also indicate that it is worthwhile to review and apply rigorous statistical approaches in studies addressing anticipation in order to reduce the influence of potential biases in future studies.

\section{Supplementary Material}

Refer to Web version on PubMed Central for supplementary material.

\section{Acknowledgements}

We thank the individuals and families who contributed to this registry of high-risk families. This work was supported in part by American Cancer Society, National Institutes of Health/National Cancer Institute, the Breast 
Cancer Research Foundation, the Ralph and Marion Falk Medical Research Trust, and Susan G. Komen Foundation.

Funding: This study was supported by the National Cancer Institute and American Cancer Society grants (MRSG-13-063-01-TBG to D.H., CRP-10-119-01-CCE to O.I.O., and P50 CA125183 to D.H. and O.I.O.)

\section{REFERENCES}

1. Kremer EJ, Pritchard M, Lynch M, et al. Mapping of DNA instability at the fragile X to a trinucleotide repeat sequence $\mathrm{p}(\mathrm{CCG}) \mathrm{n}$. Science. 1991; 252:1711-4. [PubMed: 1675488]

2. Ranen NG, Stine OC, Abbott MH, et al. Anticipation and instability of IT-15 (CAG)n repeats in parent-offspring pairs with Huntington disease. American journal of human genetics. 1995; 57:593602. [PubMed: 7668287]

3. Tsilfidis C, MacKenzie AE, Mettler G, Barcelo J, Korneluk RG. Correlation between CTG trinucleotide repeat length and frequency of severe congenital myotonic dystrophy. Nature genetics. 1992; 1:192-5. [PubMed: 1303233]

4. Deighton C, Criswell LA, Lum RF, Silman A. Ages of onset suggestive of genetic anticipation in rheumatoid arthritis multicase sibships can be explained by observational bias. Rheumatology (Oxford). 2007; 46:120-3. [PubMed: 16754627]

5. Yaturu S, Bridges JF, Dhanireddy RR. Preliminary evidence of genetic anticipation in type 2 diabetes mellitus. Med Sci Monit. 2005; 11:CR262-5. [PubMed: 15917716]

6. Brix TH, Petersen HC, Iachine I, Hegedus L. Preliminary evidence of genetic anticipation in Graves' disease. Thyroid. 2003; 13:447-51. [PubMed: 12855011]

7. Matsunaga E. Hereditary retinoblastoma: delayed mutation or host resistance? American journal of human genetics. 1978; 30:406-24. [PubMed: 717402]

8. Nilbert M, Timshel S, Bernstein I, Larsen K. Role for genetic anticipation in Lynch syndrome. J Clin Oncol. 2009; 27:360-4. [PubMed: 19075283]

9. Westphalen AA, Russell AM, Buser M, et al. Evidence for genetic anticipation in hereditary nonpolyposis colorectal cancer. Hum Genet. 2005; 116:461-5. [PubMed: 15772852]

10. Brown BW, Costello TJ, Hwang SJ, Strong LC. Generation or birth cohort effect on cancer risk in Li-Fraumeni syndrome. Hum Genet. 2005; 118:489-98. [PubMed: 16284780]

11. Tabori U, Nanda S, Druker H, Lees J, Malkin D. Younger age of cancer initiation is associated with shorter telomere length in Li-Fraumeni syndrome. Cancer research. 2007; 67:1415-8. [PubMed: 17308077]

12. Trkova M, Prochazkova K, Krutilkova V, Sumerauer D, Sedlacek Z. Telomere length in peripheral blood cells of germline TP53 mutation carriers is shorter than that of normal individuals of corresponding age. Cancer. 2007; 110:694-702. [PubMed: 17567834]

13. Bucalossi P, Veronesi U. Some observations on cancer of the breast in mothers and daughters. Br J Cancer. 1957; 11:337-47. [PubMed: 13499783]

14. Morse DP. The hereditary aspect of breast cancer in mother and daughter. Cancer. 1951; 4:745-8. [PubMed: 14859195]

15. Heredity, OJ. Breast Cancer. Busck; Copenhagen: 1946.

16. Dagan E, Gershoni-Baruch R. Hereditary breast/ovarian cancer--pitfalls in genetic counseling. Clin Genet. 2001; 60:310-3. [PubMed: 11683778]

17. Paterson AD, Kennedy JL, Petronis A. Evidence for genetic anticipation in non-Mendelian diseases. American journal of human genetics. 1996; 59:264-8. [PubMed: 8659536]

18. Peixoto A, Salgueiro N, Santos C, et al. BRCA1 and BRCA2 germline mutational spectrum and evidence for genetic anticipation in Portuguese breast/ovarian cancer families. Fam Cancer. 2006; 5:379-87. [PubMed: 16826315]

19. Paterson AD, Naimark DM, Huang J, et al. Genetic anticipation and breast cancer: a prospective follow-up study. Breast Cancer Res Treat. 1999; 55:21-8. [PubMed: 10472776]

20. Thorlacius S, Sigurdsson S, Bjarnadottir H, et al. Study of a single BRCA2 mutation with high carrier frequency in a small population. American journal of human genetics. 1997; 60:1079-84. [PubMed: 9150155] 
21. Martinez-Delgado B, Yanowsky K, Inglada-Perez L, et al. Genetic anticipation is associated with telomere shortening in hereditary breast cancer. PLoS Genet. 2011; 7:e1002182. [PubMed: 21829373]

22. Litton JK, Ready K, Chen H, et al. Earlier age of onset of BRCA mutation-related cancers in subsequent generations. Cancer. 2012; 118:321-5. [PubMed: 21913181]

23. Hopper JL, Jenkins MA. Modeling the probability that Ashkenazi Jewish women carry a founder mutation in BRCA1 or BRCA2. American journal of human genetics. 1999; 65:1771-6. [PubMed: 10577931]

24. Chen S, Parmigiani G. Meta-analysis of BRCA1 and BRCA2 penetrance. J Clin Oncol. 2007; 25:1329-33. [PubMed: 17416853]

25. Newman B, Austin MA, Lee M, King MC. Inheritance of human breast cancer: evidence for autosomal dominant transmission in high-risk families. Proceedings of the National Academy of Sciences of the United States of America. 1988; 85:3044-8. [PubMed: 3362861]

26. Easton DF, Narod SA, Ford D, Steel M. The genetic epidemiology of BRCA1. Breast Cancer Linkage Consortium. Lancet. 1994; 344:761. [PubMed: 7915813]

27. Eeles RA, Stratton MR, Goldgar DE, Easton DF. The genetics of familial breast cancer and their practical implications. European journal of cancer. 1994; 30A:1383-90. [PubMed: 7999429]

28. Claus EB, Risch N, Thompson WD. Genetic analysis of breast cancer in the cancer and steroid hormone study. American journal of human genetics. 1991; 48:232-42. [PubMed: 1990835]

29. King MC, Marks JH, Mandell JB, New York Breast Cancer Study G. Breast and ovarian cancer risks due to inherited mutations in BRCA1 and BRCA2. Science. 2003; 302:643-6. [PubMed: 14576434]

30. Easton DF, Bishop DT, Ford D, Crockford GP. Genetic linkage analysis in familial breast and ovarian cancer: results from 214 families. The Breast Cancer Linkage Consortium. American journal of human genetics. 1993; 52:678-701. [PubMed: 8460634]

31. Struewing JP, Hartge P, Wacholder S, et al. The risk of cancer associated with specific mutations of BRCA1 and BRCA2 among Ashkenazi Jews. N Engl J Med. 1997; 336:1401-8. [PubMed: 9145676]

32. Antoniou A, Pharoah PD, Narod S, et al. Average risks of breast and ovarian cancer associated with BRCA1 or BRCA2 mutations detected in case Series unselected for family history: a combined analysis of 22 studies. Am J Hum Genet. 2003; 72:1117-30. [PubMed: 12677558]

33. Ford D, Easton DF, Stratton M, et al. Genetic heterogeneity and penetrance analysis of the BRCA1 and BRCA2 genes in breast cancer families. The Breast Cancer Linkage Consortium. Am J Hum Genet. 1998; 62:676-89. [PubMed: 9497246]

34. Narod SA. Earlier age of onset in BRCA carriers-anticipation or cohort effect?: A Countercurrents Series. Current oncology. 2011; 18:257-8. [PubMed: 22184484]

35. Larsen K, Petersen J, Bernstein I, Nilbert M. A parametric model for analyzing anticipation in genetically predisposed families. Statistical applications in genetics and molecular biology. 2009; 8 Article26.

36. Brook JD, McCurrach ME, Harley HG, et al. Molecular basis of myotonic dystrophy: expansion of a trinucleotide (CTG) repeat at the $3^{\prime}$ end of a transcript encoding a protein kinase family member. Cell. 1992; 68:799-808. [PubMed: 1310900]

37. Segui N, Pineda M, Guino E, et al. Telomere length and genetic anticipation in Lynch syndrome. PloS one. 2013; 8:e61286. [PubMed: 23637804]

38. Berry DA, Iversen ES Jr. Gudbjartsson DF, et al. BRCAPRO validation, sensitivity of genetic testing of BRCA1/BRCA2, and prevalence of other breast cancer susceptibility genes. Journal of clinical oncology : official journal of the American Society of Clinical Oncology. 2002; 20:270112. [PubMed: 12039933]

39. Gabai-Kapara E, Lahad A, Kaufman B, et al. Population-based screening for breast and ovarian cancer risk due to BRCA1 and BRCA2. Proc Natl Acad Sci U S A. 2014; 111:14205-10. [PubMed: 25192939]

40. Jemal A, Center MM, DeSantis C, Ward EM. Global patterns of cancer incidence and mortality rates and trends. Cancer Epidemiol Biomarkers Prev. 2010; 19:1893-907. [PubMed: 20647400] 
41. Siegel RL, Miller KD, Jemal A. Cancer statistics, 2015. CA Cancer J Clin. 2015; 65:5-29. [PubMed: 25559415]

42. Colditz GA, Bohlke K. Priorities for the primary prevention of breast cancer. CA Cancer J Clin. 2014; 64:186-94. [PubMed: 24647877]

43. Tryggvadottir L, Sigvaldason H, Olafsdottir GH, et al. Population-based study of changing breast cancer risk in Icelandic BRCA2 mutation carriers, 1920-2000. J Natl Cancer Inst. 2006; 98:11622. [PubMed: 16418514]

44. Ning XH, Zhang N, Li T, et al. Telomere shortening is associated with genetic anticipation in Chinese Von Hippel-Lindau disease families. Cancer research. 2014; 74:3802-9. [PubMed: 24986515]

45. Bergman A, Einbeigi Z, Olofsson U, et al. The western Swedish BRCA1 founder mutation 3171 ins5; a $3.7 \mathrm{cM}$ conserved haplotype of today is a reminiscence of a 1500-year-old mutation. European journal of human genetics : EJHG. 2001; 9:787-93. [PubMed: 11781691]

46. Narod SA. Modifiers of risk of hereditary breast cancer. Oncogene. 2006; 25:5832-6. [PubMed: 16998497] 


\section{Table 1}

\section{Characteristics of Study Samples}

\begin{tabular}{|l|c|c|c|}
\hline & $\begin{array}{c}\text { Breast } \\
\text { cancer } \\
\text { family }\end{array}$ & $\begin{array}{c}\text { Ovarian } \\
\text { cancer } \\
\text { family }\end{array}$ & Total* \\
\hline Number of families & 155 & 36 & $176^{*}$ \\
\hline Number of families with BRCA1 mutation & 94 & 29 & 113 \\
\hline Number of families with BRCA2 mutation & 61 & 7 & 63 \\
\hline Number of family members with breast cancer & 579 & 74 & 587 \\
\hline Predicted number of mutation carriers in breast cancer patients & 469.1 & 60.5 & 477.1 \\
\hline Number of family members with ovarian cancer & 59 & 81 & 105 \\
\hline Predicted number of mutation carriers in ovarian cancer patients & 56.5 & 77.7 & 111.3 \\
\hline Probands with breast cancer & 96 & 12 & 100 \\
\hline Probands with ovarian cancer & 10 & 8 & 14 \\
\hline Probands with breast and ovarian cancer & 7 & 3 & 8 \\
\hline
\end{tabular}


Table 2

Anticipation effect in families with $B R C A 1 / 2$ mutations

\begin{tabular}{|l|l|l|l|l|l|l|l|l|}
\hline & \multicolumn{4}{|l|}{ Breast Cancer $(\mathbf{N}=\mathbf{5 7 9})$} & \multicolumn{3}{l|}{ Ovarian Cancer $(\mathbf{N}=\mathbf{8 1})$} \\
\hline Generation & $\mathbf{N}$ & $\begin{array}{l}\text { Mean } \\
\mathbf{A o O}^{\dagger}\end{array}$ & $\mathbf{\Delta} \mathbf{A o O}(\mathbf{9 5 \%} \mathbf{C I})$ & P-value & $\mathbf{N}$ & $\begin{array}{l}\text { Mean } \\
\text { AoO }^{\dagger}\end{array}$ & $\mathbf{\Delta} \mathbf{A o O}(\mathbf{9 5 \%} \mathbf{C I})$ & P-value \\
\hline Grandparents' gen & 81 & 51.8 & $9.8(6.3,13.4)$ & $<0.001$ & 14 & 57.1 & $8.4(1.8,15.0)$ & 0.013 \\
\hline Parents' gen & 225 & 48.7 & $6.8(4.6,9.1)$ & $<0.001$ & 36 & 53.5 & $4.8(0.1,9.5)$ & 0.048 \\
\hline Probands' gen & 242 & 41.9 & $0($ ref $)$ & & 27 & 48.8 & O (ref) & \\
\hline Children's gen & 31 & 34.7 & $-7.2(-11.8,-2.7)$ & 0.002 & 4 & 38.3 & $-10.5(-20.4,-0.6)$ & 0.038 \\
\hline
\end{tabular}

$t^{\dagger}$ mutation probability-weighted age of onset in years

Abbreviations: : $\Delta \mathrm{AoO}$, difference in years of age of onset; $\mathrm{CI}$, confidence intervals; gen, generation; ref, reference. 
Table 3

Anticipation effect in families with $B R C A 1 / 2$ mutations after controlling for ascertainment bias

\begin{tabular}{|l|l|l|l|l|l|l|l|l|}
\hline & \multicolumn{3}{|l|}{$\begin{array}{l}\text { Breast Cancer, probands excluded } \\
\text { (N=447) }\end{array}$} & \multicolumn{4}{|c|}{ Ovarian Cancer, probands excluded (N=67) } \\
\hline Generation & N & $\begin{array}{l}\text { Mean } \\
\text { AoO }\end{array}$ & $\mathbf{\Delta} \mathbf{A o O}(\mathbf{9 5 \%} \mathbf{C I})$ & P-value & $\mathbf{N}$ & $\begin{array}{l}\text { Mean } \\
\text { AoO }\end{array}$ & $\Delta$ AoO (95\% CI) & P-value \\
\hline Grandparents' gen & 81 & 51.5 & $10.5(6.6,14.3)$ & $<0.001$ & 14 & 56.9 & $8.6(1.7,15.5)$ & 0.014 \\
\hline Parents' gen & 189 & 48.0 & $7.0(4.2,9.7)$ & $<0.001$ & 32 & 52.7 & $4.4(-1.0,9.8)$ & 0.11 \\
\hline Probands' gen & 146 & 41.0 & $0(\mathrm{ref})$ & & 19 & 48.3 & $0(\mathrm{ref})$ & \\
\hline Children's gen & 31 & 35.0 & $-6.0(-10.7,1.3)$ & 0.013 & 2 & 37.9 & $-10.4(-24.2,3.3)$ & 0.14 \\
\hline
\end{tabular}

${ }^{t}$ mutation probability-weighted age of onset in years

Abbreviations: $\Delta \mathrm{AoO}$, difference in years of age of onset; $\mathrm{CI}$, confidence intervals; gen, generation; ref, reference. 
Table 4

Generational and birth cohort effects in age of onset and breast and ovarian cancers

\begin{tabular}{|c|c|c|c|c|c|}
\hline & \multicolumn{3}{|c|}{ Univariate model } & \multicolumn{2}{|c|}{ Multivariable model $^{*}$} \\
\hline & $\begin{array}{l}\text { Mean AoO } \\
+\end{array}$ & $\Delta \mathrm{AoO}(95 \% \mathrm{CI})$ & P-value & $\begin{array}{l}\text { Adjusted } \Delta \text { AoO } \\
(95 \% \text { CI })\end{array}$ & P-value \\
\hline \multicolumn{6}{|c|}{ Breast Cancer $(\mathrm{N}=378)$} \\
\hline \multicolumn{6}{|l|}{ Generation } \\
\hline Grandparents' gen & 51.6 & $5.1(0.4,9.7)$ & 0.033 & $1.8(-3.5,7.2)$ & 0.51 \\
\hline Parents'gen & 49.6 & $3.1(-0.4,6.5)$ & 0.086 & $0.9(-3.0,4.8)$ & 0.64 \\
\hline Probands' gen & 46.5 & 0 (ref) & & 0 (ref) & \\
\hline Children's gen & 44.9 & $-1.6(-14.8,11.6)$ & 0.81 & $-1.0(-14.1,12.0)$ & 0.88 \\
\hline \multicolumn{6}{|l|}{ Birth Cohort } \\
\hline $1855-1919$ & 53.5 & 0 (ref) & & 0 (ref) & \\
\hline $1920-1929$ & 49.9 & $-3.6(-8.3,1.0)$ & 0.13 & $-3.5(-8.2,1.1)$ & 0.14 \\
\hline 1930-1939 & 48.5 & $-5.0(-9.4,-0.7)$ & 0.024 & $-4.7(-9.2,-0.2)$ & 0.043 \\
\hline 1940-1949 & 45.9 & $-7.6(-11.9,-3.3)$ & 0.001 & $-6.7(-11.7,-1.7)$ & 0.009 \\
\hline \multicolumn{6}{|c|}{ Ovarian Cancer $(\mathbf{N}=58)$} \\
\hline \multicolumn{6}{|l|}{ Generation } \\
\hline Grandparents' gen & 57.0 & $5.6(-2.8,14.0)$ & 0.19 & $1.9(-7.7,11.4)$ & 0.70 \\
\hline Parents' gen & 49.6 & $2.1(-4.7,8.9)$ & 0.54 & $0.3(-7.6,8.1)$ & 0.95 \\
\hline Probands' gen & 53.6 & 0 (ref) & & 0 (ref) & \\
\hline Children's gen & 44.2 & $-7.3(-29.0,14.4)$ & 0.51 & $-7.8(-28.9,13.2)$ & 0.47 \\
\hline \multicolumn{6}{|l|}{ Birth Cohort } \\
\hline $1855-1919$ & 58.9 & 0 (ref) & & 0 (ref) & \\
\hline $1920-1929$ & 57.2 & $-1.7(-9.4,6.1)$ & 0.67 & $-1.2(-9.4,6.9)$ & 0.76 \\
\hline 1930-1939 & 48.5 & $-10.3(-17.8,-2.8)$ & 0.007 & $-9.7(-17.7,-1.8)$ & 0.016 \\
\hline 1940-1949 & 53.0 & $-5.9(-13.7,2.0)$ & 0.14 & $-4.3(-13.9,5.4)$ & 0.39 \\
\hline
\end{tabular}

* multivariable model include both generation and birth cohort so these two effects were adjusted each other.

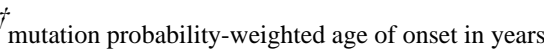

Abbreviation: $\Delta$ AoO, difference in years of age of onset; CI, confidence intervals; ref, reference. 
Table 5

Review of anticipation studies in breast cancer

\begin{tabular}{|c|c|c|c|}
\hline Reference & $\mathbf{N}$ & Population & $\begin{array}{l}\text { Anticipation } \\
\text { effect for BC } \\
\text { (years) }\end{array}$ \\
\hline Jacobsen, $1946^{15}$ & $\begin{array}{l}21 \\
(\mathrm{~m} / \mathrm{d} \text { pairs })\end{array}$ & Familial breast cancer & 11 \\
\hline Morse, $1951^{14}$ & $\begin{array}{l}13 \\
(\mathrm{~m} / \mathrm{d} \text { pairs })\end{array}$ & Familial breast cancer & 10.5 \\
\hline Bucalossi, $1957^{13}$ & $\begin{array}{l}58 \\
(\mathrm{~m} / \mathrm{d} \text { pairs })\end{array}$ & Familial breast cancer & 4 \\
\hline Paterson, $1996^{17}$ & $\begin{array}{l}59 \\
(\mathrm{~m} / \mathrm{d} \text { pairs })\end{array}$ & Familial breast cancer & 6.5 \\
\hline Thorlacius, $1997^{20}$ & $\begin{array}{l}12 \\
(\mathrm{~m} / \mathrm{d} \text { pairs })\end{array}$ & $B R C A 2$ carriers & NSS \\
\hline Paterson, $1999^{19}$ & $\begin{array}{l}67 \\
(\mathrm{~m} / \mathrm{d} \text { pairs })\end{array}$ & Familial breast cancer & NSS \\
\hline Dagan, $2001^{16}$ & $\begin{array}{l}98 \\
(\mathrm{~m} / \mathrm{d} \text { pairs })\end{array}$ & $\begin{array}{l}\text { Ashkenazi women (17 BRCA1; } \\
12 \text { BRCA2) }\end{array}$ & $\begin{array}{l}\text { BRCA1 }- \text { NSS } \\
\text { BRCA2 - } 18 \\
\text { Total }-7.18\end{array}$ \\
\hline Peixoto, $2006^{18}$ & $\begin{array}{l}44 \\
\text { (families) }\end{array}$ & $\begin{array}{l}\text { Familial breast/ovarian cancer } \\
(15 B R C A 1 ; 7 \text { BRCA2) }\end{array}$ & 9.5 \\
\hline Martinez-Delgado, $2011^{21}$ & $\begin{array}{l}623 \\
(\mathrm{~m} / \mathrm{d} \text { pairs })\end{array}$ & $\begin{array}{l}\text { Familial breast cancer ( } 40 \\
B R C A 1 ; 52 \text { BRCA2; BRCAX 531) }\end{array}$ & $\begin{array}{l}\text { BRCA1 }-6.8 \\
\text { BRCA2 - } 12.1 \\
\text { BRCAX - } 12.3\end{array}$ \\
\hline Litton, $2012^{22}$ & $\begin{array}{l}106 \\
\text { (families) }\end{array}$ & $B R C A 1 / 2$ carriers & 7.9 \\
\hline $\begin{array}{l}\text { Guindalini, } 2015 \\
\text { (current study) }\end{array}$ & $\begin{array}{l}176 \\
\text { (families) }\end{array}$ & $\begin{array}{l}\text { BRCA1/2 carriers ( } 113 \text { BRCA1; } \\
63 \text { BRCA2) }\end{array}$ & $\begin{array}{l}\text { BRCA1 }-5.8 \\
\text { BRCA2 }-8.4 \\
\text { Total }-6.8\end{array}$ \\
\hline
\end{tabular}

Abbreviation: BC, breast cancer; m/d, mother/daughter; NSS, not statistically significant 